\title{
PORQUE O SISTEMA CONFEA/CREA É NECESSÁRIO: MUDAR, NÃO EXTINGUIR
}

Mauro Conti Pereira (1) (maurocp@gmail.com), Fabrizio Leonardi ${ }^{(2)}$ (fabrizio@fei.edu.br), Alexsandro Monteiro Carneiro ${ }^{(1)}$ (almocams@gmail.com), Naji Rajai Nasri Amas ${ }^{(1)}$ (naji@ucdb.br) Marco Aurélio Candia Braga ${ }^{(4)}$ (marcoaurelio@cba.eco.br)

(1) Universidade Católica Dom Bosco (UCDB); Cursos de Engenharia de Controle e Automação, de Computação, Elétrica e Mecânica (2) Instituto Federal de Educação, Ciência e Tecnologia do Mato Grosso do Sul (IFMS): curso de Técnico em Eletrotécnica (3) Centro Universitário FEl; Departamento de Engenharia Mecânica

(4) Federação Nacional da Engenharia Mecânica e Industrial (FENEMI)

RESUMO: Este artigo foca na utilidade da existência dos conselhos profissionais no Brasil, em particular o de engenharia, explicando sua real importância na proteção da sociedade e como mecanismo indutor de desenvolvimento em regiões isoladas. Isto é necessário pois em anos recentes se tem discutido muito a possibilidade de estrangeiros atuarem no pais, assim como recém-graduados acharem que o sistema não tem serventia. Além disso, existe o "pecado" que a maioria das instituições de ensino de engenharia cometem, na falta de divulgação do papel dos conselhos profissionais e do exercício profissional aos futuros egressos. Elas também não veem a necessidade de seus docentes serem registrados no respectivo conselho. Talvez isso ocorra porque muitos professores, especialmente nas universidades públicas, se formam e não chegam a atuar fora da área acadêmica por muito tempo no mercado de trabalho, não tendo contato com o conselho. Este trabalho visa esclarecer estes pontos e justificar a necessidade do CONFEA. Procura-se também salientar os problemas de sombreamento entre diferentes modalidades e niveis de cursos (técnicos $x$ tecnólogos $x$ engenheiros), e sugere a existência de exames de proficiência para acabar com as discussões de sombreamento, de exercício profissional de estrangeiros e de egressos mal formados, seja presencialmente ou em EAD.

PALAVRAS-CHAVE: ENGENHARIA, CREA, CONSELHO PROFISSIONAL, EXAME DE PROFICIÊNCIA, CERTIFICAÇÃO

\section{WHY A PROFESSIONAL COUNCIL IS NEDEED}

ABSTRACT: This paper intends to justify the existence of professional organizations to regulate professions in Brazil, especially in engineering. It highlights its protection of the society and its induction of development in distant regions. In recent years the discussion of foreign professional coming to work in Brazil has increased, as recently graduated engineers feel that the council is not useful for them. Also, most colleges do not inform their students the real purposes of professional councils and how to plan their careers. They also do not understand the need for the registration of their teachers in the councils, which have had little contact with professional organizations. This work tries to clarify certain topics and to reverse this feeling. It also points out some overlapping between different engineering areas and course levels (technician $x$ engineer, for example). It suggests certification tests to end discussions of overlapping, of foreign professionals, and of alumni not properly prepared, either from face-to-face classes or from distance learning.

KEYWORDS: ENGINEERING, CREA, PROFESSIONAL COUNCIL, PROFESSIONAL TESTING, CERTIFICATION 


\section{XIX CENEMI}

\section{INTRODUÇÃO}

Em anos recentes muito se tem discutido sobre a utilidade de conselhos profissionais, em especial o sistema CONFEA/CREA. Este artigo se refere a este sistema, regulamentado pela lei 5194 de 1966, denominado Conselho Federal de Engenharia, Arquitetura e Agronomia (CONFEA - depois os arquitetos saíram em final de 2010, o A permanece devido à agronomia), e os Conselhos Regionais de cada estado (CREA). Mas no texto quando se refere a CREA ou a CONFEA, normalmente se refere ao sistema como um todo, exceto quando citado o CREA de um estado específico.

A maioria dos profissionais formados reclama que o CREA não o defende, confundindo com sindicatos, quando na realidade será mostrado que seu papel principal é defender a sociedade, semelhante ao DETRAN, setor que regulamenta veículos e seus condutores. As instituições de ensino têm pecado na instrução do exercício profissional de seus egressos, tanto sobre conselhos profissionais como quanto ao planejamento de suas carreiras.

Outro problema comum é que vários gestores de instituições de ensino acham que engenheiro atuando como professor não devia ser fiscalizado pelo CREA, mas a lei 5194 no seu artigo 7ọ prevê isso, como discutido adiante. Além disso, se uma pessoa para participar de um concurso tem de possuir diploma de engenheiro, como se pode depois argumentar que ele não está atuando como engenheiro ao lecionar e pesquisar?

Também muito se tem dito sobre atuação de profissionais estrangeiros vindo para o Brasil. Em 2016 por exemplo, projetos de lei começaram a ser debatidos (mais a seguir), e com a mudança de presidente isto se reforçou.

No correr do artigo inicialmente se descreve o sistema atual, sua composição e principais regras. Depois se descreve algumas normas internacionais que podem impactar o sistema, e por último são apresentados argumentos defendendo a manutenção do sistema. Não que ele não possa ser melhorado, com certeza pode e deve, mas não deve simplesmente ser extinto como alguns advogam.

Até quem cita que em alguns países do exterior não exista conselho nos moldes do CREA, sempre existe um departamento responsável por veículos automotores e seus condutores. Ninguém em sã consciência acharia que qualquer interessado poderia sair dirigindo uma carreta de 30 toneladas ou um ônibus escolar, assim age-se preventivamente inibindo que isso possa ser feito. No caso dos conselhos profissionais como o de engenharia, em que as consequências de algo malfeito podem ser catastróficas, a situação é semelhante, há que se prevenir e não apenas punir depois que alguém faz algo errado, pois os custos em vidas ou materiais poderia se irreparável.

Finalmente, é defendida a implantação de exames de proficiência para se poder exercer a profissão, o que ajudaria a resolver problemas de sombreamentos entre áreas e entre níveis (técnico x engenheiro, por exemplo), e até a entrada de profissionais estrangeiros para exercer engenharia no país. Ele serviria ainda para ajudar a separar os profissionais mal formados, seja em cursos presenciais ou mesmo os em educação

Como a Engenharia Mecânica e Industrial podem melhorar o Agronegócio do Brasil Anais do XiX CONEMI - Congresso Nacional de Engenharia Mecânica e Industrial | $\mathbf{2}$ de $\mathbf{2 3}$ 


\section{XIX CONEMI}

a distância (EAD), tão questionados em meses recentes por diversos outros conselhos como veterinária, enfermagem e arquitetura, gerando grandes batalhas judiciais.

\section{O ESTUDO E EXERCICIO PROFISSIONAL DA ENGENHARIA NO BRASIL}

A seguir apresenta-se a descrição de como se estuda e se exerce a engenharia (e profissões correlatas) e a organização do sistema CONFEA/CREA/MUTUA, seus representantes e normas.

\subsection{MEC X CREA}

A legislação que criou os cursos de agronomia e engenharias são decretos antigos, desde 1933, mas a lei que organizou o conselho profissional foi a 5194 de 1966, complementada por outras específicas para cada área, detalhadas no item seguinte. Esta lei dá ao CONFEA a possibilidade de legislar sobre a atuação profissional em engenharia, conforme detalhado adiante.

Assim, segundo a legislação vigente, o MEC (Ministério da Educação, federal, mas que mantém a sigla da época em que Ministério da Educação e Cultura) cuida das condições de ensino de cada curso (o que e como deve ser ensinado em quanto tempo), enquanto o conselho profissional dita o que o egresso pode fazer quando sai para o mercado de trabalho (que depende do que estudou), bem como qual título deve possuir dentro do sistema CONFEA/CREA.

Se não existir o mesmo título do curso no MEC e no CONFEA, pode-se fazer um requerimento para adicionar novos títulos, mas isto demora muitos meses ou anos, pois deve ser feita uma solicitação ao CONFEA, em Brasília, portanto normalmente se prefere buscar o título mais aproximado.

CONFEA é Conselho FEDERAL enquanto CREA é o REGIONAL de cada estado, por exemplo CREA-MS, CREA-RJ, CREA-SP, e assim por diante. É usual se referir ao sistema CONFEA/CREA mencionando apenas CREA.

O CREA não pode fazer ingerência nos cursos, e quando uma escola solicita registro do curso, apenas pode analisar o que é estudado e dar atribuições correspondentes, restringindo a atuação nas coisas em que o profissional não estudou. No máximo costuma-se sugerir melhorias após análise de projeto pedagógico nos cursos apresentado quando do pedido de registro do curso, para que o egresso não tenha restrições nas suas atribuições profissionais. Na prática, os pareceres dos conselheiros do CREA acabam quase se tornando consultorias gratuitas, pois em geral os conselheiros que os realizam são professores de universidades e fazem várias sugestões, desde infraestrutura até de bibliografia.

Como a Engenharia Mecânica e Industrial podem melhorar o Agronegócio do Brasil Anais do XiX CONEMI - Congresso Nacional de Engenharia Mecânica e Industrial | $\mathbf{3}$ de $\mathbf{2 3}$ 


\section{XIX CONEMI}

\subsection{ORGANIZAÇÃO DO SISTEMA CONFEA/CREA}

O decreto federal 23569 de 1933 regulamentou as profissões de Engenharia e Arquitetura, entre outras, e a Agronomia foi regulamenta pelo 23186 também de 1933, ambos no governo Getúlio Vargas.

Em 1966 surgiu a lei 5194, quer regulamenta as profissões de engenheiro, arquiteto e agrônomo. Tanto nos decretos quanto na lei, foi incluído o que se estuda e pode fazer profissionalmente, como registrar, e assim por diante. A lei ainda deu poder ao CONFEA para criar normas e regulamentos que definem as atribuições e detalhamento dos procedimentos do sistema. Isto é feito através de resoluções amplamente discutidas, e de decisões plenárias. Assim a profissão segue a seguinte ordenamento jurídico: Constituição Federal, Leis, Decreto-lei, Decretos, Resoluções e Decisões normativas e decisões plenárias do CONFEA, e Atos normativos de cada CREA, válidos apenas no estado correspondente ao CREA que os cria. Um bom local para conhecer todas estas normas é o próprio site do CONFEA, em:

( http://normativos.confea.org.br/apresentacao/apresentacao.asp)

Em 1966 surgiu a lei 4950 que determina os salários mínimos de engenheiros, arquitetos, agrônomos e veterinários, apenas para empresas privadas, pois para órgãos públicos foi vetado o artigo correspondente. Basicamente cita que o engenheiro deve receber 6 salários mínimos (SM) de sua região (depois foi unificado no Brasil todo) para uma jornada de trabalho de 6 horas diárias, e 1,25 SM a cada hora diária adicional, resultando em 8,5 SM para uma jornada normal de 8 horas diárias.

Alguns CREAs como o do MS, criaram a figura da empresa especial, em que o profissional pode manter uma carga horária menor que 6 horas diárias, e responder por várias pequenas empresas, ganhando menos em cada uma, mas viabilizando a existência de um responsável técnico capacitado em empresas de menor porte. (https://www.creams.org.br/wpcontent/uploads/2017/04/instrucao-normativa-021-fl3.jpg)

Em 1977 a lei 6496 criou as anotações de responsabilidade técnica (ART) e parte do dinheiro arrecadado vai para uma caixa de assistência denominada Mutua, que financia em diversas situações o professional associado, tais como ter filho, compra de material profissional, carro e reforma, entre outros. (http://www.mutua.com.br)

Conforme mencionado, em dezembro de 2010 a lei 12378 criou conselho separado dos arquitetos (CAU) e em 2018 a lei 13638 criou o conselho federal dos técnicos. Os técnicos industriais (da área civil, elétrica e mecânica) saíram em 2018, os técnicos agrícolas ainda não se organizaram para sair.

Como a Engenharia Mecânica e Industrial podem melhorar o Agronegócio do Brasil Anais do XiX CONEMI - Congresso Nacional de Engenharia Mecânica e Industrial | $\mathbf{4}$ de 23 


\section{XIX CENEMI}

Assim, o CONFEA, originalmente Conselho Federal de Engenharia, Arquitetura e Agronomia passou em 2011 a ser o Conselho Federal de Engenharia e Agronomia (apesar de englobar outras profissões afins como agrimensor, geólogo, meteorologista, entre outras).

O sistema é dividido em grupos (ou categorias): Agronomia (incluindo engenheiros florestais e agrícolas e meteorologistas) e Engenharias. Arquitetura era um grupo, mas saiu quando foi criado seu conselho em final de 2010 (CAU).

O grupo de engenharias é subdividido em modalidades (1:civil, 2:elétrica, 3:mecânica e metalurgia, 4:química, 5:geologia e minas, e 6:agrimensura).

Cada grupo e modalidade tem três níveis: graduação plena, tecnólogo, e técnicos de nível médio, e cada título é descrito na resolução 473 , revisada periodicamente. Destaca-se que os técnicos saíram do sistema, mas os títulos ainda existem, pois muitos profissionais acumulam título em mais de um nível. Além disso, apesar do conselho dos técnicos ter sido criado na lei de 2018, eles deveriam ter saído em março, mas os técnicos industriais (construção civil, eletrotécnica, mecânica e outros) saíram apenas em dezembro, e os técnicos agrícolas ainda não saíram até o momento deste artigo (agosto de 2019).

Existe também a especialização em Segurança do Trabalho, para todos os graduados de nível superior. Pode-se também registrar eventuais cursos pós-graduação latu-sensu (especializações) ou strictu-sensu (mestrado e doutorado), mas estes apenas em condições especiais acrescentam atribuições ao profissional, mas este não é o escopo deste artigo.

\section{Representantes no CREA}

Cada CREA é composto por representantes da sociedade civil organizada, como sindicatos, associações profissionais e as próprias instituições de ensino superior, denominados conselheiros. Há um número limitado total de conselheiros para ser rateado entre os sindicatos e associações, que depende da quantidade de profissionais registrados no estado. Adicionalmente há representantes das instituições de ensino superior que tenham cursos na área. Elas podem ter um representante por grupo, ou seja, se tiver curso em Agronomia e vários de engenharia, poderá ter um representante de cada grupo. $O$ representante das engenharias normalmente se reveza entre as modalidades, a cada 3 anos muda.

O conselheiro tem mandato de 3 anos, podendo ser reconduzido por mais três anos, tendo de esperar por pelo menos um ano para voltar para um eventual terceiro mandato, desde que representando outra associação. Se for da mesma associação, tem de esperar 3 anos. A cada ano, um terço dos representantes totais é trocado, sendo chamado o processo de "renovação do terço".

Como a Engenharia Mecânica e Industrial podem melhorar o Agronegócio do Brasil Anais do XiX CONEMI - Congresso Nacional de Engenharia Mecânica e Industrial | $\mathbf{5}$ de 23 


\section{XIX CENEMI}

Os conselheiros estaduais se reúnem em câmaras especializadas, dependendo da quantidade de profissionais de cada área existentes no estado, e para existir uma câmara deve haver pelo menos 3 profissionais da área específica. No MS existem 4 câmaras especializadas (CE): Agronomia, EST (Engenharia de Segurança de Trabalho), CEEECA (câmara especializada de engenharia civil e agrimensura) e CEEEM (câmara especializada de engenharia elétrica e mecânica). Em outros estados como SP, com mais profissionais, podem haver mais subdivisões. Os problemas relativos a outras áreas que não tenham câmara especializada num determinado estado, por exemplo engenharia química ou de minas, são resolvidos no plenário com todos os conselheiros juntos.

Existem também comissões com representantes de cada câmara, para discutir problemas específicos como educação e atribuições profissionais (CEAP), meio ambiente, ética, legislação profissional, renovação do terço (ou seja, renovação de $1 / 3$ dos conselheiros a cada ano) e eleições, entre outras. As comissões não têm poder deliberativo, apenas consultivo, ou seja, sugerem pareceres que podem ou não ser acatados pelas câmaras.

No MS geralmente se reúnem uma vez por mês, de manhã as comissões, a tarde as câmaras, e a noite a plenária com todos os conselheiros, onde se ratificam (confirmam) as decisões das câmaras.

Quando não se chega a uma decisão na plenária, por exemplo num caso de sombreamento entre modalidades, encaminha-se a disputa para o CONFEA.

Cada CREA é presidido por um presidente eleito por votação direta de todos os profissionais registrados no estado (ou de outro estado, mas com visto naquele estado), com mandato de 3 anos, podendo ser reeleito uma vez. Diferente de outros conselhos como OAB, em que a diretoria é eleita em chapa junto com o presidente, no CREA o resto da diretoria (inclusive os vice-presidentes) é escolhido anualmente entre os conselheiros, na primeira reunião plenária. Isto dificulta que um determinado grupo mande arbitrariamente no conselho pela duração do mandato, dificultando a predominância de um grupo ou modalidade sobre outros.

O presidente do CONFEA também é eleito da mesma maneira, e a diretoria também é escolhida a partir dos conselheiros federais, que são eleitos um representante por estado, independente do grupo ou modalidade, com mandato de 3 anos. Porém, como na época da lei 5194 haviam menos estados, existem apenas 18 representantes, e há rodízio dos estados e modalidades, ficando alguns estados sem representante em certos períodos. Eles se reúnem mensalmente em Brasília.

Como a Engenharia Mecânica e Industrial podem melhorar o Agronegócio do Brasil Anais do XiX CONEMI - Congresso Nacional de Engenharia Mecânica e Industrial | $\mathbf{6}$ de 23 


\section{XIX CONEMI}

\section{Atividades dos conselheiros}

Nas reuniões de câmara se discutem os pareceres em cima dos processos analisados por cada conselheiro, bem como se definem regras e comentários em cima de propostas do CONFEA ou mesmo do congresso nacional. O parecer de um processo é feito baseado na regulamentação (leis, decretos, resoluções, normas...) e definem se haverá penalidade e qual seria a penalidade, que então é votada na câmara, e depois acatada (ou não) na plenária a noite.

Um processo é aberto depois que um fiscal visita uma obra ou empresa e checa se existe projeto ou serviço executado por responsável habilitado. Vale destacar que o fiscal não precisa ser um profissional do sistema, pois ele não analisa tecnicamente se um projeto está bem feito, apenas se existe um profissional habilitado respondendo pelo projeto ou execução de algo.

Outro tipo de processo para registrar curso, onde ele passa por alguém que vai analisar o processo com projeto pedagógico e documentos oficiais como reconhecimento do curso e ART de cargo e função (ou diploma) dos professores da área técnica. As regras mudaram um pouco desde os decretos de 33 , as resoluções 218/73, 1010/05 e 1073/16, mas basicamente baseado no que se estuda, é definido o que se pode fazer (as atribuições do professional formado no curso). Da mesma forma, o parecer de um curso deve ser aprovado na câmara e depois na plenária. No CREA-MS cursos tradicionais vão direto para as câmaras, mas se for de um curso novo, diferente do habitual, passa primeiro pela CEAP (comissão de educação e atribuições profissionais) para um parecer consultivo. Cursos que não tem câmara vão direto para algum relator pelo plenário.

Existem dois tipos de problemas que se tenta coibir no exercício profissional:

- Profissionais fazendo aquilo que não estudaram ("exorbitância": por exemplo civil querendo fazer sistema de som ou cabine de força de uma instalação elétrica industrial, um mecânico querer fazer uma linha de transmissão de energia elétrica ou um eletricista querer fazer instalações de ar condicionado central);

- Pessoas não habilitadas fazendo coisas sem ter estudado ("exercício ilegal da profissão": por exemplo, algum leigo fazer instalação de cerca elétrica ou de cabeamento estruturado de computadores).

Também se respondem dúvidas da sociedade e se definem áreas de sombreamento, em coisas que poderiam ser feitas por duas modalidades diferentes, descritas mais adiante.

Observe ainda que o CREA não é sindicato para defender profissional, ele é o DETRAN da engenharia que existe para checar se alguém está fazendo apenas aquilo que cursou, detalhamos mais a seguir. Se aprendeu ou não, se esqueceu, se é sério ou não, isto o CREA não tem como checar. Assim, ele não checa se um prédio foi bem construído, apenas se quem se responsabiliza pelo 


\section{XIX CENEMI}

projeto estudou para isso. Funciona semelhante a um guarda de trânsito que não checa se alguém é bom motorista, apenas se ele fez os exames e obteve a CNH (carteira nacional de habilitação). CREA não existe para criar reserva de mercado, mas para proteger a sociedade, mas ao inibir os leigos do mercado, acaba protegendo os bons profissionais que tiveram a formação adequada.

\subsection{PRINCIPAIS RESOLUÇÕES E ATRIBUIÇÕES:}

As principais resoluções do CREA são:

- As que regularizam e subdividem as áreas de atuação de todos os níveis de profissionais, a 218 de 1973, 1010 de 2005 e 1073 de 2016;

- 473/02 que define os títulos;

- $1007 / 03$ que define registro de profissionais;

- 1008 que define penalidades;

- 1016 que altera a 1007 e 1010;

- 1018/06 sobre registro de universidades e associações;

- 1023/08 e 1025/09 sobre ART e acervo técnico;

- Além de algumas especificas para tecnólogos (313/86) e técnicos (262/79 e 278/83).

Assim, quem formou até 1973 tinha atribuições dadas pelos decretos de 1933, chamados popularmente de "decretão", onde se achava que praticamente todos podiam quase tudo, até mecânico e eletricista fazer edificações ou civis fazerem trabalharem com máquinas, por exemplo mas existem restrições, pois muitas coisas específicas estão listadas apenas em algumas modalidades, se todos pudessem tudo não haveria necessidade do legislador detalhar algumas atividades específicas.

Quem se formou após 1973, é regido pela 218/73, 1010/5 e 1073/16, e várias outras resoluções específicas. Outras modalidades não detalhadas na 218 são cobertas em outras resoluções, as principais listadas abaixo:

- De Produção: $235 / 75$ e 288/83

- De Materiais: $241 / 76$

- Agrícola: $256 / 78$

- De Pesca: $279 / 83$

- Químico têxtil: $308 / 86$

- Sanitarista: 310/86

- Ambiental: $447 / 00$

- Avaliações e Perícias: 345/90

- Segurança do Trabalho: 359/91

- De Computação: 380/93

- Hídrico: 492/06

- De Aquicultura: 493/06

Como a Engenharia Mecânica e Industrial podem melhorar o Agronegócio do Brasil Anais do XiX CONEMI - Congresso Nacional de Engenharia Mecânica e Industrial | $\mathbf{8}$ de $\mathbf{2 3}$ 


\section{XIX CoNEMI}

- De Controle e automação: 427/99

- De Software: $1100 / 18$

Atribuições

Explicando melhor as atribuições que se recebe ao formar-se: na resolução atual, 218 , que vale desde 1973, o egresso assume as atribuições de alguma modalidade, podendo apenas restringir atribuições, e se fizer alguma especialização pode aumentar suas atribuições apenas dentro da mesma área. Por exemplo, um engenheiro civil que não tenha estudado pontes e estradas pode sair com atribuições na civil, mas sem poder fazer pontes e estradas. Depois, se fizer especialização nisso, pode obter estas atribuições. Ou um engenheiro naval, da área mecânica, que fizer especialização em refrigeração e ar condicionado, poderia trabalhar com isso também.

No caso de um engenheiro de computação, pode ter atribuições do artigo 9 (eletrônica) atuando apenas em sistemas digitais, mas não em instalações elétricas (do artigo 8) ou responsabilizar-se por emissora de TV ou por telefonia, por exemplo. Depois, se fizer especialização em controle ou telecomunicações, por exemplo, pode aumentar atribuições também nestas áreas.

Já um engenheiro eletricista pleno, pode ter atribuições de ambos artigos, 8 (eletrotécnica) e 9 (eletrônica). Conforme mencionado antes, estas restrições eram dadas no momento em que o curso é cadastrado no CREA do estado da instituição de ensino, quando o projeto pedagógico é analisado pelos conselheiros da respectiva câmara, passando antes por uma comissão de especialistas que compõe a CEAP (comissão de educação e atribuições profissionais). A partir da 1073/16 existe uma orientação do CONFEA para não dar restrições, mas especificar o que o egresso pode fazer.

A CEAP é formada normalmente por professores de universidades que representam as instituições de ensino ou sindicatos e associações. O membro da CEAP sugere um parecer que pode ou não ser seguido pela comissão, que depois de aprovado pela comissão é encaminhado à respectiva câmara, que pode ou não acatar a sugestão da CEAP. Depois, o parecer da câmara é referendado na plenária à noite com todos os conselheiros de todas as áreas - por isso as atribuições podem variar de estado para estado. Porém, na prática, para cursos de graduação na maioria das vezes não se restringe as atribuições, dando o artigo completo. Isto é claro na redação do artigo 10 da 1016 que alterou a 1007:

Art. $1^{\circ}$ Os arts. 11, 15 e 19 da Resolução no 1.007, de 5 de dezembro de 2003, passam a vigorar com a seguinte redação:

"A câmara especializada competente atribuirá o título, as atividades e as competências profissionais em função da análise da qualificação acadêmica do portador de diploma ou certificado, de acordo com os procedimentos e os critérios estabelecidos em resolução específica."

Como a Engenharia Mecânica e Industrial podem melhorar o Agronegócio do Brasil Anais do XiX CONEMI - Congresso Nacional de Engenharia Mecânica e Industrial | 9 de 23 


\section{XIX CENEMI}

A partir da resolução 1010, que vale para quem começou a estudar a partir de julho de 2007, depois substituída pela 1073 de 2016, pode-se assumir atribuições de várias modalidades, e até de outro grupo, dependendo do que CADA ALUNO estudou. Observe que pela 218 a análise era feita no cadastro do curso. Agora na 1010 e 1073 é feito o cadastro da escola e do curso, MAS para cada aluno deveria ser feita uma análise, pois até mesmo dois alunos da mesma turma, que fizerem optativas diferentes poderão ter diferentes atribuições, complicando muito a análise. A 1010 previa uma matriz de conhecimentos para identificar o que cada um devia estudar para atuar num setor específico, mas depois ela foi abandonada. Estava previsto um sistema informatizado para fazer estas análises desde 2009, mas ainda não se concluiu.

Observe ainda que alguns dos nomes usados nos catálogos nacionais de cursos técnicos (CNCT) e tecnológicos (CNCST) podem ter nomes diferentes da tabela de títulos do CREA, e precisa ainda ser consultado qual seria o nome exato.

\section{Sombreamento}

Também, às vezes há discussões entre câmaras nas áreas de sombreamento, em que se tem dúvida sobre se uma atividade é exclusiva de uma modalidade ou pode ser feita por várias. Por exemplo:

- Antigamente, agrônomo discutindo com arquiteto sobre quem faz gramado de futebol e paisagismo;

- $\quad$ arquiteto e engenheiro civil querendo fazer demarcação urbana que seria de agrimensor;

- agrônomo querendo demarcar áreas rurais que seria de agrimensor (apesar de existir uma plenária definindo que para processos do INCRA eles poderiam);

- agrônomo x engenheiro florestal sobre quem pode fazer reflorestamento;

- civil querendo ser responsável por empresa metalúrgica que faz vigas metálicas para de construção;

- civil achando que pode fazer qualquer coisa de elétrica (por exemplo, cabine de força, grupo gerador ou para-raios) por ter estudado uma disciplina de 60 horas do básico de eletricidade, e assim por diante.

Na realidade a maioria dos engenheiros civis, por não ter estudado a fundo a área de instalações elétricas, não podem fazer medição agrupada (vilas) e de prédios por exemplo, nem instalações industriais, apenas instalações residenciais mais simples de residências unifamiliares. Se estudou mais a fundo, há meios de comprovar usando as normas internas (resoluções), para solicitar extensão das atribuições.

Como a Engenharia Mecânica e Industrial podem melhorar o Agronegócio do Brasil Anais do XiX CONEMI - Congresso Nacional de Engenharia Mecânica e Industrial | $\mathbf{1 0}$ de $\mathbf{2 3}$ 


\section{XIX CENEMI}

\section{"DECRETÃO" DE 1933}

Por exemplo, ainda existem profissionais que possuem as atribuições do comumente chamado "decretão" (decreto federal 23569 de 1933) que primeiro regulamento a profissão de engenheiro (o 23186 para agronomia) e em teoria daria possibilidade de qualquer um fazer qualquer coisa. Ele valeu até a instalação da lei 5194/66 que alterou e expandiu o sistema CONFEA/CREA e lhe deu o poder de legislar sobre o assunto. Porém, como na lei 5194 não aparece o tradicional "deixam de valer as regras anteriores", muitos argumentam que estes decretos ainda valem.

Então o CONFEA criou a resolução 218 /73 que explicitou as atribuições gerais das principais áreas, e depois foi criando outras resoluções para novas engenharias que foram surgindo desde então (produção, controle e automação, pesca, sanitária, ...), portanto há quem diga que quem formou até 73 teria atribuição de tudo, e quem formou depois seria pela resolução 218 . Existe muita briga sobre isso, alguns argumentou que não existiria uma lei que explicitamente cancelasse o decretão, alguns civis no plenário do CREA-MS defendem esta tese, mas mesmo que assim o fosse, ao se ler o decreto de 33 , observa-se que não é tão simples assim. Coisas que deveriam ser especificas de uma área está explicitado no artigo da área. Por exemplo, construção de portos e saneamento está explicitado dentro da área civil, no artigo 29. Outras atividades como distribuição de energia estão explicitadas no artigo dos engenheiros eletricistas. Se todos pudessem fazer tudo, não seria necessário explicitar.

- $\quad$ Art. 28. São da competência do engenheiro civil:

a) trabalhos topográficos e geodésicos;

b) o estudo, projeto, direção, fiscalização e construção de edifícios, com tôdas as suas obras complementares;

c) o estudo, projeto, direção, fiscalização e construção das estradas de rodagem e de ferro: d) o estudo, projeto, direção, fiscalização e construção das obras de captação $e$ abastecimento de água;

e) o estudo, projeto, direção, fiscalização e construção de obras de drenagem e irrigação; f) o estudo, projeto, direção, fiscalização e construção das obras destinadas ao aproveitamento de energia e dos trabalhos relativos às máquinas e fábricas;

g) o estudo, projeto, direção, fiscalização e construção das obras relativas a portos, rios e canais e dos concernentes aos aéroportos;

h) o estudo, projeto, direção, fiscalização e construção das obras peculiares ao saneamento urbano e rural;

i) projeto, direção e fiscalização dos serviços de urbanismo;

j) a engenharia legal, nos assuntos correlacionados com a especificação das alíneas a a i;

l) perícias e arbitramentos referentes à matéria das alíneas anteriores.

- $\quad$ Art. 29. Os engenheiros civis diplomados segundo a lei vigente deverão ter: a) aprovação na cadeira de "Portos de mar, rios e canais", para exercerem as funções de Engenheiro de Portos, Rios e Canais;

Como a Engenharia Mecânica e Industrial podem melhorar o Agronegócio do Brasil Anais do XiX CONEMI - Congresso Nacional de Engenharia Mecânica e Industrial | 11 de $\mathbf{2 3}$ 


\section{XIX CONEMI}

b) aprovação na cadeira de "Saneamento e Arquitetura" para exercerem as funções de Engenheiro Sanitário;

c) aprovação na cadeira de "Pontes e grandes estruturas metálicas e em concreto armado", para exercerem as funções de Engenheiro de Secções Técnicas, encarregadas de projetar e executar obras de arte, nas estradas de ferro e de rodagem;

d) aprovação na cadeira de "Saneamento e Arquitetura", para exercerem funções de urbanismo ou de Engenheiro de Secções Técnicas destinadas a projetar grandes edifícios.

Parágrafo único. Sòmente engenheiros civis poderão exercer as funções a que se referem as alíneas $a$, b e c dêste artigo.

-Art. 30. Consideram-se da atribuição do arquiteto ou engenheiro-arquiteto

a) o estudo, projeto, direção, fiscalização e construção de edifícios, com tôdas as suas obras complementares;

b) o estudo, projeto, direção, fiscalização e construção das obras que tenham caráter essencialmente artístico ou monumental;

c) o projeto, direção e fiscalização dos serviços de urbanismo;

d) o projeto, direção e fiscalização das obras de arquitetura paisagística;

e) o projéto, direção e fiscalização das obras de grande decoração arquitetônica;

f) a arquitetura legal, nos assuntos mencionados nas alíneas a e c dêste artigo;

g) pericias e arbitramentos relativos à matéria de que tratam as alíneas anteriores.

-Art. 33. São da competência do engenheiro eletricista :

a) trabalhos topográficos e geodésicos;

b) a direção, fiscalização e construção de edifícios;

c) a direção, fiscalização e construção de obras de estradas de rodagem e de ferro;

d) a direção, fiscalização e construção de obras de captação e abastecimento de água;

e) a direção, fiscalização e construção de obras de drenagem e irrigação;

f) a direção, fiscalização e construção das obras destinadas ao aproveitamento de energia e dos trabalhos relativos as máquinas e fábricas;

g) a direção, fiscalização e construção de obras concernentes às uzinas elétricas e às rêdes de distribuição de eletricidade;

h) a direção, fiscalização e construção das instalações que utilizem energia elétrica:

i) assuntos de engenharia legal, relacionados com a sua especialidade;

j) vistorias e arbitramentos concernentes à matéria das alíneas anteriores.

\section{Título do profissional}

Com relação aos títulos, se não existir na tabela de títulos da resolução 473 do CONFEA o nome exato do curso, não batendo com as tabelas de convergência do MEC, deve-se buscar o mais aproximado, para não demorar o registro dos egressos. Por exemplo, no CONFEA existe título de técnico em mecatrônica, mas não de engenheiro mecatrônico. Apesar de o engenheiro mecatrônico estudar a maior parte do que vê um engenheiro eletricista, e muito do mecânico, e apesar de ter uma resolução (427) descrevendo suas atribuições, costuma ser classificado como engenheiro de controle a automação (ECA), que fica dentro da modalidade eletricista do grupo engenharias.

Observe que na resolução 218 o mecânico tinha atribuições do artigo 12, e o engenheiro eletricista tinha o artigo 8, que cobre a parte de eletrotécnica (instalações elétricas, geração,

Como a Engenharia Mecânica e Industrial podem melhorar o Agronegócio do Brasil Anais do XiX CONEMI - Congresso Nacional de Engenharia Mecânica e Industrial | $\mathbf{1 2}$ de $\mathbf{2 3}$ 


\section{XIX CENEMI}

transmissão e distribuição de eletricidade) e o artigo 9 é o de eletrônica (computação, comunicações, sistemas eletrônicos em geral). Já o mecatrônico em geral estuda tudo que o ECA estuda e mais vários de tópicos específicos da área mecânica, mas na vigência da resolução 218 , não fica "com um pé" em cada área (mecânica e eletrônica), fica apenas na área elétrica (artigos 8 e 9), eventualmente com alguma restrição, dependendo do estado (no MS pega quase tudo do elétrico, com restrições em média e alta tensão).

Em 2009 o MEC criou uma convergência dos títulos de técnicos no CNCT (Catálogo Nacional de Cursos Técnicos) e tecnólogos no CNCST (Catalogo Nacional de Cursos Superiores de Tecnologia). Em 2011 o MEC diminuiu de 258 tipos de engenharia para 22, mas depois, após manifestações da sociedade, voltou para cerca de 30 . Assim, os cursos de mecatrônica tiveram de mudar de nome para ECA (engenharia de controle e automação).

(http://portal.mec.gov.br/docman/novembro-2017-pdf/77451-cnct-3a-edicao-pdf-1/file) (http://portal.mec.gov.br/index.php?option=com docman\&view=download\&alias=44501 -cncst-2016-3edcpdf\&category slug=junho-2016-pdf\&ltemid=30192)

\subsection{REGISTRO DE CURSO E TÍTULOS}

Para que o egresso (formado) de um curso possa atuar profissionalmente, o curso deve ter registro no CREA. Para isso é necessário encaminhar ao CREA os mesmos projetos pedagógicos de curso (PPC) que escolas particulares ou estaduais de ensino médio normalmente encaminhariam à secretaria de educação do estado, ou que faculdades e universidades encaminham ao MEC.

Normalmente os PPC vêm listando, entre outros: justificativa e objetivos do curso, como ingressar, perfil profissional dos egressos, organização curricular (grade de disciplinas), cronograma de implantação, horário de funcionamento, total de horas do curso, total de vagas por turma, prazo de integralização (duração em semestres ou anos), disciplinas, resumo cruzando competências e habilidades que se espera obter a partir de cada disciplina, metodologia de ensino, estágio profissional obrigatório, critérios de aproveitamento de conhecimentos e experiências anteriores, critérios de avaliação, instalações e equipamentos de laboratórios, convênios para uso de labs em empresas, acervo bibliográfico disponível aos alunos, pessoal docente e técnico envolvido no curso, e modelo do diploma expedido pelo curso.

Para garantir que quem leciona uma disciplina técnica tenha o conhecimento necessário, deve-se incluir a ART (ou diploma) de professores das disciplinas técnicas específicas.

Por exemplo, Cientista de Computação não pode dar aula de cabeamento estruturado, mesmo que tenha feito cursos da Furukawa depois de formado. Arquiteto não pode dar aula de instalações elétricas industriais, e assim por diante. Administrador não pode lecionar Segurança do Trabalho em curso de graduação mesmo que tenha feito Técnico em Segurança do Trabalho.

Como a Engenharia Mecânica e Industrial podem melhorar o Agronegócio do Brasil Anais do XiX CONEMI - Congresso Nacional de Engenharia Mecânica e Industrial | $\mathbf{1 3}$ de $\mathbf{2 3}$ 


\section{XIX CENEMI}

Para matérias não específicas cobertas pelos profissionais do CREA, pode ser outro profissional: por exemplo, pode ter físico, matemático, químico, entre outros, dando aula de cálculo, física, mecânica geral, química, não precisa ser engenheiro químico, por exemplo. Ou cientista de computação dando aula de Eletrônica Digital ou Arquitetura de Computadores pode, mas não de Telecomunicações, por exemplo.

\subsection{ART E A RESPONSABILIDADE DO PROFISSIONAL}

Como mencionado, a anotação de responsabilidade técnica (ART) foi criada por uma lei de 1977. Mas o destaque vale para a palavra "responsabilidade", pois ao assinar o profissional se responsabiliza civil e criminalmente pela obra e eventuais problemas. Mesmo que alguém tenha atribuição, não deve fazer algo que não domina ou assinar projeto ou execução que outro tenha feito sem que ele confira o serviço. Responsabilidade civil quer dizer que se estragar algo ou danificar algo em decorrência de algum problema técnico que devia ter sido previsto, o profissional que assinou deve cobrir o prejuízo. Responsabilidade criminal quer dizer que se alguém morre quando explode uma caldeira ou um equipamento de hospital falha ou uma instalação elétrica industrial ocasiona ferimentos ou morte de alguém, o profissional que assinou pode ir para a cadeia. Não vale a pena correr risco por causa de 400 ou 500 reais mensais para assinar por alguma empresa que só tenha pessoas que aprenderam na prática e precisa de um responsável técnico, ou por exemplo um engenheiro civil assinar uma obra pronta sem conferi-la. Quem assinar por uma empresa, deve supervisionar os serviços realizados. Aliás, quem assina sem checar pode sofrer um processo de ética e até perder seu registro, são os populares "caneteiros".

\section{Professores devem se registrar}

Aliás, muito professor, coordenador e diretor de faculdade achava ridículo CREA quando exigia ART de engenheiro que só lecionasse, e ganharam liminares, parece que em MG e SP contra isso, apesar que o artigo 7 da lei 5194 que regulamentou a profissão diz que ensino é uma das atividades dos engenheiros.

Art. 70--As atividades e atribuições profissionais do engenheiro, do arquiteto e do engenheiroagrônomo consistem em:

d) ensino, pesquisa, experimentação e ensaios;

...

Não se sabe como algo tão claro numa lei pode ter tido uma interpretação diferente de um juiz. Assim, a partir dessas liminares o CONFEA orientou a não exigir mais ART de professor, então no CREA-MS ao se cadastrar um curso, exige-se do gestor que os docentes, se não tiverem ART, pelo

Como a Engenharia Mecânica e Industrial podem melhorar o Agronegócio do Brasil Anais do XiX CONEMI - Congresso Nacional de Engenharia Mecânica e Industrial | 14 de 23 


\section{XIX CENEMI}

menos apresentem titulação para garantir que o professor tenha visto na sua graduação o tópico essencial da área do curso que esteja lecionando.

Talvez essa exigência seja desnecessária na USP, FEI, Unicamp, ITA, MAUA, UFRGS, PUC ou UFRJ, entre outras tradicionais, mas quando se analisa algumas instituições particulares que parecem estar preocupadas apenas com a mensalidade e quantidade de alunos, isso fica preocupante e a regra tem de existir para todos. E afinal, a ART de cargo e função só se fazia uma vez para toda a vida do profissional, custava cerca de 80 reais, mesmo que a USP tivesse 300 professores na elétrica, isso custaria apenas uma vez $300 \times 40=12$ mil reais pela vida toda. Não acho que seria algo que se precisasse brigar tanto, o custo judicial acaba ficando maior.

Mas pelo menos cobrar titulação na área, os diplomas de quem leciona, mesmo que não pague ART, achamos imprescindível.

O mais incrível é que, além de estar claro no artigo 70 da lei 5194, para se candidatar a um concurso, é necessário possuir diploma de engenheiro, então não faz sentido depois dizer que o professor não está atuando como engenheiro ao lecionar.

\section{Mutua - Caixa de assistência}

E para o profissional professor, que não atuasse mais no mercado, mesmo que nunca fizesse uma consultoria que fosse, ainda seria interessante pagar a anuidade do CREA porque isso permite que ele tenha acesso à MUTUA para obter empréstimos muito mais baratos que em bancos para construir, reformar, quitar dívidas, comprar carro, estudar, pagar nascimento de filho, tirar férias, equipar-se profissionalmente. Lembro que $20 \%$ do valor das ARTs vai para MUTUA, e outros $\%$ ia para as associações de classe tipo ABEMEC, ANEST, ABEE, ABEC. Se acabar a ART vai acabar também o dinheiro da Mutua e talvez até inviabilizar as associações que defendem os profissionais, que somos nós e nossos egressos.

\subsection{A AMEAÇA DO ACORDO INTERNACIONAL E DA PEC108}

Existe um Acordo Multilateral de Investimentos (AMI), decorrente do Consenso de Washington, sendo negociado. Adiante pode-se ver as recomendações do trabalho elaborado pelo Núcleo de Estudos Pesquisas da Consultoria Legislativa do Senado Federal, acerca da abertura do mercado da Engenharia ao capital estrangeiro, constam várias medidas de cerceamento da atuação do CONFEA/CREAs, entre elas:

- Retirar do Conselho Federal de Engenharia e Arquitetura (CONFEA) e dos respectivos conselhos regionais (CREAs) o poder de veto sobre o registro de diplomas de estrangeiros (alínea c do art. 2o da Lei no 5.194/1966);

Como a Engenharia Mecânica e Industrial podem melhorar o Agronegócio do Brasil Anais do XiX CONEMI - Congresso Nacional de Engenharia Mecânica e Industrial | $\mathbf{1 5}$ de $\mathbf{2 3}$ 


\section{XIX CENEMI}

- Revogar o poder do CONFEA e dos CREAs para autorizar e controlar o "exercício legal da profissão" e o funcionamento de entidades do setor (Lei no 5.194/1966: art. 6o, alínea a; art. 24; art. 26; as alíneas c do art. 27; e alínea d do art. 46);

- Revogar o poder de CONFEA e CREAs para relacionar os cargos e funções de entidades estatais e paraestatais privativos de engenheiros, arquitetos e agrônomos (Lei no 5.194/1966, alínea g do art. 27);

- Extinguir a "Anotação de Responsabilidade Técnica" (ART) (Lei no 6.496/1977 e Lei no 5.194/1966, art. 28, inciso I);

- Revogar o poder do CONFEA e dos CREAs para definir tabelas de remuneração profissional (Lei no 5.194/1966, art. 34, alínea r);

- Extinguir o direito de cobrança de anuidades (e de punição por inadimplência em tal cobrança) pelo CONFEA e CREAs, bem como de taxas de registros e multas (Lei no 5.194/1966, art. 35, incisos I, III, IV e V; e arts. 63,64 e 69);

- Extinguir a obrigatoriedade de manter assistente brasileiro junto a profissional de engenharia estrangeiro (Lei no 5.194/1966, art. 85);

- Revisão de todas as resoluções vigentes do Conselho.

(http://www12.senado.gov.br/publicacoes/estudos-legislativos/tipos-de-estudos/textos-para-

discussao/td171 acessado em 10 de novembro de 2016)

Além disso, foi proposta recentemente a PEC 108 de 2019 que questiona a necessidade dos conselhos profissionais.

https://www.camara.leg.br/proposicoesWeb/fichadetramitacao?idProposicao=2211437

https://www.camara.leg.br/propostas-legislativas/2211437

\section{ARGUMENTOS A FAVOR DA MANUTENÇÃO DO SISTEMA}

À primeira vista parece que o CREA/CONFEA não serve para nada, eu também pensava que só queriam nosso dinheiro da ART e não faziam nada, mas depois que um dos autores passou 6 anos como conselheiro no CREA-MS representando a universidade em que leciona, viu-se que muita coisa é importante. Evita-se por exemplo que curiosos tentem fazer coisas perigosas como dar manutenção em caldeira que pode explodir, controlar reações químicas em indústrias que podem vazar ou explodir, ou instalar elevadores ou instalações elétricas industriais sem o devido preparo.

Incluem-se aí autodidatas e o pessoal de Ciência de Computação que acha que tudo é apenas programação, e que qualquer um poderia atuar nisso - sem formação nem em programação - existia um projeto de lei para isso, que liberaria qualquer um fazer qualquer coisa que envolvesse programação. $O$ que aconteceria se os matemáticos também quisessem que qualquer um poderia aprender cálculo e equações diferenciais sozinho, e que assim, tudo que envolvesse equações

Como a Engenharia Mecânica e Industrial podem melhorar o Agronegócio do Brasil Anais do XiX CONEMI - Congresso Nacional de Engenharia Mecânica e Industrial | 16 de 23 


\section{XIX CENEMI}

diferenciais poderia ser liberado para qualquer um atuar? A turma da SBC (Sociedade Brasileira de Computação) esquece que até reator nuclear envolve programação e seria liberado para qualquer um fazer caso o projeto de lei tivesse sido aprovado.

Incluem-se também arquitetos que desde 2011 criaram um conselho a parte e liberaram para si mesmo tudo, até projeto de incêndio e instalações industriais, de elevadores, entre outros muitos apenas contratam o serralheiro que faz seu portão eletrônico e se assumem a responsabilidade de fazer o equivalente deles da ART, a RRT (registro de responsabilidade técnica), mas a realidade é que muitos cursos de arquitetura não ensinam nem a fazer cálculo estrutural ou instalação elétrica residencial de maneira completa.

Outros riscos que se devem evitar:

- Curiosos construindo em barrancos que depois desmoronam na primeira chuva; (isso ocorre agora, imagine se liberasse geral...);

- Curiosos e decoradores reformando apartamentos arrancando colunas, de prédios que depois desmoronam como no RJ há alguns anos atrás;

- Um leigo ou profissional de outra área tentando projetar ou operar uma instalação de tratamento de água e esgotos, imagine as consequências se algo dá errado...

- Imagine alguém da sua família ser hospitalizado numa UTI onde o responsável pela manutenção dos equipamentos seja um curioso ou autodidata qualquer. Uma vez no CREAMS tentaram colocar um técnico em eletrotécnica do SENAl, recém-formado, como responsável por empresa de equipamentos hospitalares, e obviamente fui contra e não deixei na época que isso ocorresse. Afinal, no passado um técnico desses até poderia ser melhor que um leigo total, mas não atualmente com a maior quantidade de profissionais disponíveis, pois eles focam mais em quadros elétricos, instalações elétricas e geração, transmissão e distribuição de energia, não em circuitos eletrônicos avançados. O ideal é um engenheiro com especialização em engenharia clínica ou engenheiro biomédico que seja responsável por este tipo de equipamento hospitalar.

Também fui contra uma vez que em que vi que num curso técnico do interior de MS o professor de segurança de trabalho era um administrador de empresas, e o de instalações elétricas industriais era um arquiteto... coisas que eles nunca tinham visto, só estavam lá para tapar buraco. Isto é diferente um Cientista de Computação lecionar arquitetura de computadores ou eletrônica digital num curso de engenharia de computação ou eletrônica, eles veem isso na graduação. Mas não veem cabeamento estrutura de redes de computadores e telefonia, costumam focar apenas na programação de drivers e protocolos de comunicação das redes.

Como a Engenharia Mecânica e Industrial podem melhorar o Agronegócio do Brasil Anais do XiX CONEMI - Congresso Nacional de Engenharia Mecânica e Industrial | 17 de 23 


\section{XIX CONEMI}

\subsection{EMPRESAS NECESSITAM DE VISTO}

Empresas de um estado atuem em outro sem estado ter alguém competente no local vistoriando tudo, por exemplo, em grandes instalações industriais como usinas de álcool, por exemplo. Um pequeno erro de instalação ou controle ou manutenção e pode haver, no mínimo, vazamentos que podem danificar o meio ambiente por anos, além do perigo para operadores caso não haja mais vistoria de engenheiros de segurança...;

Por exemplo: o projetista dos prédios do IFMS de Campo Grande, MS, era do Paraná, e não considerou os regulamentos da concessionária de energia d a região (ENERSUL), e criou um desperdício de dinheiro público, pois fez de acordo com as normas da CEPEL do Paraná. Estava tudo errado nas entradas de energia, ia ter de ser refeito, e fui informado de que quem ganhou a licitação tinha de seguir o projeto para só depois fazer uma nova licitação para corrigir os erros. Até em 2016 vários prédios, que deviam estar prontos em 2009, ainda não estavam prontos.

Assim, outra utilidade do sistema CONFEA/CREA é ser indutor de desenvolvimento nos estados mais afastados. Uma empresa de grandes centros como SP, PR, MG, RJ, RS e outros, para atuar ainda que por pouco tempo em outro estado como Mato Grosso do Sul ou Pará, deve pedir visto no estado, com endereço e profissional responsável residente no local. Isto faz com que se vá aos poucos desenvolvendo a engenharia na região em questão, caso contrário uma grande empresa viria para um estado menor, faria o trabalho em algumas semanas/meses e voltaria não deixando nenhum pessoal habilitado no projeto, montagem ou manutenção mais avançada.

\subsection{PROFISSIONAIS ESTRANGEIROS}

Deve-se evitar que alguém sem preparo de outro país venha atuar no mercado - sabe-se lá por qual motivo, seja político, ou alguém mal preparado, ou um multinacional que não queira trabalhar com brasileiros - segundo se diz nas reuniões do CREA, hoje

Já existem cerca de 70 mil técnicos e engenheiros estrangeiros atuando aqui, imagine se não existissem burocracias...por exemplo muitas normas técnicas são diferentes, e o que eu disse sobre alguém de um estado atuar em outro também se aplica para estrangeiros. Além disso se alguém vem, fica pouco tempo e vai embora, o conhecimento não permanece no pais, seremos uma eterna "república de bananas". É diferente de um especialista em petróleo da Noruega vir para cá dar consultoria, mas ele hoje tem de provar que é capacitado e deve ter alguém acompanhando para sugar ao máximo o conhecimento.

Como a Engenharia Mecânica e Industrial podem melhorar o Agronegócio do Brasil Anais do XiX CONEMI - Congresso Nacional de Engenharia Mecânica e Industrial | $\mathbf{1 8}$ de $\mathbf{2 3}$ 


\section{XIX CONEMI}

\subsection{CREA É PREVENTIVO}

Muitos acham que não tem utilidade, mas CREA é como o DETRAN. Coisas pequenas não precisam de formação especifica, é como quando qualquer poderia pegar um carro ou caminhonete numa fazenda e passear um pouco, mas não se pode pegar um ônibus escolar ou uma carreta de 30 toneladas e pôr outros em risco na estrada sem ter passado por algum tipo de treinamento e exame. Ter CNH não garante ser bom motorista, mas pelo menos passou-se por algum treinamento mínimo. Da mesma maneira, graduar-se em uma faculdade ou universidade não significa que o egresso não cometerá erros, mas garante que pelo menos passou por um treinamento mínimo. Lembro ainda que o CREA não existe para proteger o profissional, está lá para proteger a sociedade contra curiosos ou ignorantes, os mal-intencionados sem irão agir de qualquer jeito. Para defender os profissionais existem os sindicatos e associações de classe como ABEE e ABEMEC. Apesar que indiretamente o CREA ajuda os bons profissionais, pois os maus e leigos acabam tendo mais dificuldade de atuar na área. Na prática se poderia argumentar que uma pessoa mal-intencionada ainda poderia atuar, mas o objetivo é ser preventivo e dificultar, assim como a existência de $\mathrm{CNH}$ não impede um filho de roubar o carro do pai - mas o pai fica responsável por qualquer dano que o filho causar, pois é responsável pelo carro.

\subsection{EXAME DE PROFICIÊNCIA (OU EXAME DE “ORDEM")}

$O$ autor principal deste artigo era contra exame de proficiência, ou exame ordem semelhante ao da OAB ("exame de proficiência") até que algumas escolas de baixíssima qualidade apareceram há mais de uma década e começaram a formar engenheiros que não sabem nem resolver equação de segundo grau (não estou brincando, conheço alguns casos pessoalmente). Alguns argumentam que não se consegue fazer um exame completo em cada área, mas a existência do ENADE a cada 4 anos mostra que não é impossível. Quando atuei no comitê assessor na área de Controle e Automação no INEP, responsável pela criação do ENADE no triênio 2014-16, aprendi quão sério e difícil é fazer um exame, mas não impossível. (GOMES et al, 2016). E isso evitaria também as brigas entre profissões, que hoje ocorrem, tais como:

- Civis e elétricos brigando por quem pode fazer instalações elétricas industriais ou de prédios (elétricos argumentam que alguns cursos de civil não estudam a fundo isso),

- Agrônomos, e arquitetos brigando por quem pode fazer gramados de estádio e campos de golfe;

- $\quad$ Agrônomos e engenheiros florestais sobre quem pode fazer reflorestamento;

- Mecânicos e civis brigando por quem pode se responsabilizar por indústria de viga e estruturas metálicas (mecânica argumenta que não é apenas usar vigas prontas, que o civil aprende bem, seria necessário estudar materiais e metalurgia);

Como a Engenharia Mecânica e Industrial podem melhorar o Agronegócio do Brasil Anais do XiX CONEMI - Congresso Nacional de Engenharia Mecânica e Industrial | 19 de 23 


\section{XIX CENEMI}

- Muitos elétricos reclamam que civis consideram muita coisa como "atividade complementar" de uma obra civil, por exemplo construir um prédio faria os projetos elétrico, instalação de elevador, projeto de incêndio, entre outros, ser considerado apenas como complementar.

- Técnico (que vê superficialmente tudo), tecnólogo (que se aprofunda numa única subárea) e engenheiro (que se aprofunda em várias) brigam para saber quem pode fazer o quê.

Por exemplo, técnico tem um decreto lei dizendo que ele pode fazer alguns projetos. Até aí tudo bem, um técnico em edificações poderia fazer casas de até $80 \mathrm{~m} 2 \mathrm{sem}$ laje, mas não prédios, pontes ou estradas como um engenheiro civil. Mas o decreto deve ter sido assinado sem muita análise, pois técnicos em eletrotécnica pelo decreto poderiam fazer instalações de até $800 \mathrm{KVA}$, o que na prática é uma grande indústria ou pequena cidade, e quem leciona em curso técnico sabe que não estudam o suficiente para executar tudo isso. Além disso, engenharia não se trata apenas do que você estudou ou não, mas também da capacidade de aprender a estudar, a continuar se atualizando sozinho, o que não se pode dizer de um curso técnico, devido à falta de maturidade da maioria dos alunos, entre 14 e 18 anos. As aulas em cursos técnicos vão mais devagar que em cursos superiores, obviamente, e uma disciplina de 80 horas no técnico não cobre o mesmo que uma de 80 horas do superior. Engenharia, segundo o MEC, requer mínimo de 3600 horas (INEP: Referenciais Curriculares para Bacharelados e Licenciatura, abril de 2010), enquanto o técnico, segundo o MEC requer apenas 1200 horas para eletrotécnica (CNCT, Catálogo Nacional de Cursos Técnicos, do MEC, 2008). Lembro que são horas definidas como hora-relógio, de 60 minutos, portanto 3600 horas de 60 minutos resulta 4320 aulas de 50 minutos (parecer CNECEB 016/1999);

Se alguém fizesse a prova e passasse, já seria suficiente para provar que pode, até mesmo um leigo autodidata que fizesse a prova poderia obter credenciais para trabalhar numa área, o que hoje não ocorre. Se não me engano, há estados no EUA que permitem que alguém não formado em Direito exerça a profissão caso passe no exame de ordem deles (o BAR examination). Assim acabariam os problemas de sombreamento entre modalidades, entre pessoal com e sem "decretão", e entre níveis (técnico x tecnólogo x engenheiro).

A cada 3 anos há um congresso dos profissionais da área (CNP = congresso nacional de profissionais), que em assembleia define futuras regras a serem implementadas pelo sistema CONFEA/CREA. No passado eram contra o exame, e "perdia de lavada" quem propusesse isso. No penúltimo congresso (2013), foi proposto, e na votação, a proposta foi aceita para profissionais estrangeiros fazerem exame, mas para os novos engenheiros e técnicos a criação do exame de

Como a Engenharia Mecânica e Industrial podem melhorar o Agronegócio do Brasil Anais do XiX CONEMI - Congresso Nacional de Engenharia Mecânica e Industrial | 20 de $\mathbf{2 3}$ 


\section{XIX CENEMI}

proficiência perdeu por 392 a 388 - numa sala em que a contagem foi feita levantando plaquinha e com as pessoas se movimentando, e quando pediu-se recontagem o condutor da reunião, que obviamente era contra, ignorou e continuou com as votações seguintes - que inclusive passaram a ser contadas de maneira diferente. E é incrível que num congresso de profissionais de tecnologia se usasse método manual tão arcaico e passível de erros. Nos congressos seguintes pensava-se em propor durante a reunião inicial de como proceder com votações, que qualquer votação com diferença menor que $5 \%$ seja feita a recontagem sempre, para evitar manipulações. De qualquer modo, a evolução histórica das contagens mostra que as opiniões estão mudando e que no futuro pode vir a ocorrer a criação de exame estilo da OAB para os profissionais do sistema CONFEA: engenheiros, agrônomos, meteorologistas, geógrafos, agrimensores, técnicos agrícolas (industriais criaram seu conselho), tecnólogos, etc.).

Alguns professores de federais argumentam que não seria necessário exame para seus alunos de escolas tradicionais, mas como mencionado, para alguns egressos de certas instituições particulares seria sim necessário. Outros argumentam que já há muita gente e que não se pode cobrar exame deles e tirar atribuições que atualmente já possuem. Mas, fazendo analogia, se um barco está furado e entrando agua, primeiro tape o buraco, depois decida o que fazer com a água, ou deixe ela lá até evaporar. Se bloquearmos a entrada de novos profissionais despreparados no mercado de trabalho, os mau profissionais que já existem mais cedo ou mais tarde se aposentam ou morrem e no futuro o problema estaria resolvido. Se não fizermos nada, o problema continua existindo para sempre.

\subsection{FALTA DE ENGENHEIROS}

Pode-se até concordar que no Brasil precisamos de muitos engenheiros para melhorar e desenvolver o país, e que as escolas não estão formando adequadamente ou em quantidade, mas o fato também é que muito empresário também não está disposto a contratar engenheiro, ou quer engenheiro a preço de técnico (ou menos). Isso passa também por conscientização da sociedade e por melhores leis para fomentar a inovação tecnológica e industrialização no país, tal que não seja mais barato importar um projeto pronto e só montar aqui, envolvendo também alterar leis de importação para evitar isso.

\subsection{ARQUITETOS}

Por último, se o acordo em debate no congresso tirar o direito do CREA/CONFEA, teriam de tirar também os dos arquitetos no conselho deles (CAU), que por sinal escreveram em sua lei

Como a Engenharia Mecânica e Industrial podem melhorar o Agronegócio do Brasil Anais do XiX CONEMI - Congresso Nacional de Engenharia Mecânica e Industrial | 21 de 23 


\section{XIX CENEMI}

que podem fazer qualquer coisa tecnológica, até projeto de incêndio, instalação de elevador, construção de silos, etc. Em sua lei no final cita-se que casos conflitantes com outros conselhos seriam discutidos posteriormente, só que o CAU e CONFEA nunca se dispuseram a negociar de verdade, as comissões de conciliação não avançaram como deveriam. Aliás, ao ser assinada pelo então presidente Lula no último dia de seu governo, a única coisa que ele vetou foi a obrigatoriedade de salário mínimo de arquiteto, que estava na lei 4950/66 para arquitetos, engenheiros, químicos e veterinários. Os arquitetos tentaram incluir na lei do CAU, não conseguiram e ainda perderam a validade da antiga 4950 (lei dos arquitetos e urbanistas CAU 2378/10 versus lei do salário mínimo 4950/66). Lembro ainda que na 4950/66 vale a regra do salário mínimo apenas para iniciativa privada, o presidente da época vetou a parte que dizia sobre governos.

\section{CONCLUSÕES}

Extinguir o sistema CONFEA/CREA não é a melhor solução. Como citado várias vezes, o sistema é preventivo, protege a sociedade e induz o desenvolvimento de regiões remotas ou até mesmo induz a transferência de tecnologia de empresas estrangeiras que vêm atuar no Brasil, ao se exigir a presença de um profissional habilitado junto. É preventivo assim como o DETRAN, que inibe que alguém despreparado dirija uma carreta ou um ônibus escolar pondo a vida de outros em risco, assim como em outros países é feito. Atuar em engenharia pode também colocar a vida e patrimônio de outros em risco e deve continuar restrita aos poucos preparados.

Alguns profissionais argumentam que o CONFEA deveria mudar para ser um certificador, com exame opcional fazendo quem quisesse, e o mercado aos poucos exigiria que o profissional fosse certificado, como já ocorre na área de computação em banco de dados da ORACLE e em redes de computadores para certificação CISCO. Vamos ver como evolui esta questão.

É hora de as escolas de engenharia esclarecerem melhor o papel do conselho profissional a seus egressos, e de seus gestores se inteirarem da realidade dos conselhos profissionais.

Também é hora de associações e CONFEA se moverem e fazer campanhas de esclarecimentos na sociedade, outdoors, vinhetas, propaganda em TV, "merchandising" em novelas. E fazer campanha junto a deputados e senadores das consequências de seus votos caso votem de maneira equivocada. Cada profissional do sistema deveria fazer como nos EUA e escrever para o deputado e senador para quem votou e o representa, e reclamar da importância dos profissionais da área e do possível impacto que isto pode trazer ao país.

Por fim, é imprescindível que se crie o exame de proficiência, semelhante ao exame da OAB (Ordem dos Advogados do Brasil) faz, pois assim se eliminaria muitos dos problemas por sombreamento entre modalidades e entre conselhos, ou mesmo entre níveis, como técnicos versus 


\section{XIX CENEMI}

engenheiros. Nos EUA por exemplo os testes PE (professional engineer de cada modalidade) e o EIT (engineer in training, para recém-formados), e associações criam certificações especificas de cada assunto, coo ar condicionado, por exemplo. Poderiam servir de base, assim como os exames de ENADE também poderiam. O próprio INEP poderia ser contratado para isso, pois existe dinheiro no sistema, vindo das ARTs e anuidades, e o INEP já comprovou sua competência na criação do ENADE continuamente anos após ano.

\section{REFERÊNCIAS}

CONSElHO FEDERAL DE ENGENHARIA E ARQUITETURA (CONFEA). Normativos: http://normativos.confea.org.br/apresentacao/apresentacao.asp Acessado em 20 de julho de 2019.

CREA-MS: Regras para empresas especiais https://www.creams.org.br/wpcontent/uploads/2017/04/instrucao-normativa-021-fl3.jpg Acessado em 20 de julho de 2019

Caixa de Assistência aos profissionais do CREA (MUTUA) www.mutua.org.br Acessado em 20 de julho de 2019.

GOMES, A.C.D.N; MADANI, F.S.; MAIA, J.E.B.; PEREIRA, M.C.; QUEIROZ, M.H. "O ENADE instrumento de avaliação e melhoria dos cursos de engenharia de controle e automação". COBENGE 2016 - XLIV Congresso Brasileiro De Educação Em Engenharia, Natal, 2016.

MEC- Catalogo Nacional de Cursos Técnicos http://portal.mec.gov.br/docman/novembro-2017pdf/77451-cnct-3a-edicao-pdf-1/file Acessado em 20 de julho de 2019.

MEC- Catalogo Nacional de Cursos Superiores de Tecnologia http://portal.mec.gov.br/index.php?option=com_docman\&view=download\&alias=44501-cncst-2016-3edcpdf\&category_slug=junho-2016-pdf\&ltemid=30192 Acessado em 20 de julho de 2019.

\section{CAMARA DOS DEPUTADOS}

https://www.camara.leg.br/proposicoesWeb/fichadetramitacao?idProposicao=2211437 Acessado em 21 de julho de 2019.

CAMARA dos DEPUTADOS

https://www.camara.leg.br/propostas-legislativas/2211437 Acessado em 21 de julho de 2019

Como a Engenharia Mecânica e Industrial podem melhorar o Agronegócio do Brasil Anais do XiX CONEMI - Congresso Nacional de Engenharia Mecânica e Industrial | 23 de 23 